\section{BRAZIULIAN JOURNAL \\ OF MEDICAL AND BIOLOGICAL RESHARCH}

www.bjournal.com.br
ISSN 0100-879X

Volume 43 (04) 325-408 April 2010

BIOMEDICAL SCIENCES

AND

CLINICAL INVESTIGATION

Braz J Med Biol Res, March 2010, Volume 43(4) 377-389

Cardiac gene expression and systemic cytokine profile are complementary in a murine model of post-ischemic heart failure

S. Lachtermacher, B.L.B. Esporcatte, F. Montalvão, P.C. Costa, D.C. Rodrigues, L. Belem, A. Rabischoffisky, H.C.C. Faria Neto, R. Vasconcellos, S. lacobas, D.A. lacobas, H.F.R. Dohmann, D.C. Spray, R.C.S. Goldenberg and A.C. Campos-de-Carvalho

The Brazilian Journal of Medical and Biological Research is partially financed by

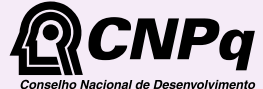

Ministério

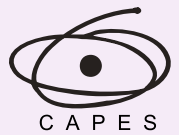

Ministério da Educação

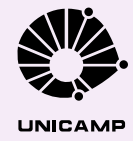




\title{
Cardiac gene expression and systemic cytokine profile are complementary in a murine model of post-ischemic heart failure
}

\author{
S. Lachtermacher ${ }^{1 *}$, B.L.B. Esporcatte ${ }^{1 *}$, F. Montalvão1, P.C. Costa ${ }^{1}$, \\ D.C. Rodrigues ${ }^{1}$, L. Belem ${ }^{2}$, A. Rabischoffisky², H.C.C. Faria Neto ${ }^{3}$, \\ R. Vasconcellos ${ }^{4}$, S. lacobas ${ }^{5}$, D.A. lacobas ${ }^{5}$, H.F.R. Dohmann ${ }^{2}$, \\ D.C. Spray ${ }^{5}$, R.C.S. Goldenberg ${ }^{1}$ and A.C. Campos-de-Carvalho ${ }^{1,5}$ \\ ${ }^{1}$ Instituto de Biofísica Carlos Chagas Filho, Universidade Federal do Rio de Janeiro, Rio de Janeiro, RJ, Brasil \\ 2PROCEP, Centro de Ensino e Pesquisa, Hospital Pró-Cardíaco, Rio de Janeiro, RJ, Brasil \\ ${ }^{3}$ Departamento de Fisiologia e Farmacodinâmica, Fundação Oswaldo Cruz, Rio de Janeiro, RJ, Brasil \\ ${ }^{4}$ Departamento de Imunobiologia, Instituto de Imunologia, Universidade Federal Fluminense, Niterói, RJ, Brasil \\ ${ }^{5}$ Albert Einstein College of Medicine, Bronx, NY, USA
}

\begin{abstract}
After myocardial infarction (MI), activation of the immune system and inflammatory mechanisms, among others, can lead to ventricular remodeling and heart failure $(\mathrm{HF})$. The interaction between these systemic alterations and corresponding changes in the heart has not been extensively examined in the setting of chronic ischemia. The main purpose of this study was to investigate alterations in cardiac gene and systemic cytokine profile in mice with post-ischemic HF. Plasma was tested for IgM and IgG anti-heart reactive repertoire and inflammatory cytokines. Heart samples were assayed for gene expression by analyzing hybridization to AECOM 32k mouse microarrays. Ischemic HF significantly increased the levels of total serum IgM (by 5.2-fold) and total IgG (by 3.6-fold) associated with a relatively high content of anti-heart specificity. A comparable increase was observed in the levels of circulating pro-inflammatory cytokines such as IL-1 $\beta$ (3.8X) and TNF- $\alpha(6.0 X)$. IFN- $\gamma$ was also increased by 3.1-fold in the MI group. However, IL-4 and IL-10 were not significantly different between the MI and sham-operated groups. Chemokines such as MCP-1 and IL-8 were 1.4- and 13-fold increased, respectively, in the plasma of infarcted mice. We identified 2079 well annotated unigenes that were significantly regulated by post-ischemic HF. Complement activation and immune response were among the most up-regulated processes. Interestingly, 21 of the 101 quantified unigenes involved in the inflammatory response were significantly up-regulated and none were down-regulated. These data indicate that post-ischemic heart remodeling is accompanied by immune-mediated mechanisms that act both systemically and locally.
\end{abstract}

Key words: Experimental post-ischemic heart failure; Anti-heart antibodies; Cytokines; Immunoarray; RNAm - Microarray

\section{Introduction}

Myocardial infarction (MI) is the most frequent cause of heart failure (HF), and the leading cause of death in Western countries (1). Several factors, including inflammation, apoptosis and immune-mediated mechanisms, culminate in adaptive changes of ventricular size, shape and function known as ventricular remodeling, which leads to $\mathrm{HF}(2,3)$. The inflammatory reaction after acute MI (AMI) is coordinated by the activity of a series of cytokines, which is a prerequisite for healing and scar formation (4-6). IFN- $\gamma$, a typical cytokine involved in the Th1-type response (7), is significantly increased in patients after AMI (8). The proinflammatory cytokines IL-1 (9) and TNF- $\alpha$ (10) have also been implicated in the inflammatory response after AMI. Chemokine expression is markedly up-regulated in AMI and may play an important role in regulating leukocyte infiltration and activity and in modulating infarct angiogenesis as well as fibrous tissue deposition (11). Although the immune-inflammatory response has been well characterized after AMI

Correspondence: A.C. Campos-de-Carvalho, Instituto de Biofísica Carlos Chagas Filho, UFRJ, CCS, Bloco G, 21949-900 Rio de Janeiro, RJ, Brasil. Fax: +55-21-2280-8193. E-mail: acarlos@biof.ufrj.br

*These authors contributed equally to this study.

Received April 28, 2009. Accepted February 18, 2010. Available online March 5, 2010. Published April 12, 2010. 
(12), far fewer studies have examined this response in the setting of healed myocardial infarctions leading to chronic heart failure $(13,14)$. Furthermore, there have been few publications correlating the systemic immune-inflammatory response to changes in gene expression in the chronically ischemic myocardium. Therefore, in the present study, we have characterized the immune and inflammatory profile persisting 7 weeks after the induction of ischemic heart failure in mice by determining serum levels of cytokines and of the anti-heart reactive IgM and IgG antibody repertoire and by concomitantly determining the cardiac gene activation profile by microarray analysis.

\section{Material and Methods}

This investigation conforms to the Guide for the Care and Use of Laboratory Animals (Institute of Laboratory Animal Research, Commission on Life Science, National Research Council, USA) and was approved by the Animal Committee of UFRJ.

\section{Animals}

Male and female C57BL/6 mice aged 8-10 weeks (20.5-25.5 g) were obtained from the Animal Facility of the Federal University of Rio de Janeiro. Mice were housed at controlled temperature $\left(23^{\circ} \mathrm{C}\right)$ with a $12: 12$-h light-dark cycle and received standard mouse chow and water ad libitum.

\section{Ischemic heart failure}

Permanent myocardial infarcts were produced by ligation of the descending branch of the left coronary artery. Animals were anesthetized by an intraperitoneal injection of ketamine $(40 \mathrm{mg} / \mathrm{kg})$ and xylazine $(80 \mathrm{mg} / \mathrm{kg})$, placed in the supine position and intubated. Mice were ventilated with a volume-cycled ventilator (100 cycles/min; Harvard Apparatus, USA) with a volume sufficient to adequately expand but not overexpand the lungs. After a left anterior thoracotomy, the heart was exposed and the suture (8-0 mononylon) was passed under the artery at a position $\sim 1$ $\mathrm{mm}$ from the tip of the normally positioned left auricle. The chest was then closed and the skin sutured with 5-0 nylon. Sham operations were carried out by the same method but without tying the suture on the left anterior descending artery (15).

\section{Electrocardiography}

Briefly, $24 \mathrm{~h}$ before infarction mice were anesthetized and electrodes were implanted subcutaneously in each limb and extended to the back of the animal where a threeprong lead was exteriorized in order to obtain a ventral plane 3-lead ECG in awake animals. ECG were recorded continuously (Power Laboratory, ADInstruments, USA), and the parameters analyzed were: heart rate, ECG intervals [PR, QRS, QT, and QTc using Bazett's methods (QTc $=$ QT/ $\left.\mathrm{RR}^{1 / 2}\right)$ ], ECG wave amplitude and duration ( $\left.\mathrm{P}, \mathrm{QRS}, \mathrm{T}\right)$,
ST amplitude, and presence of $Q$ wave in $L 1$, which were recorded starting $24 \mathrm{~h}$ after surgery and thereafter.

\section{Myocardial damage markers}

Blood was obtained from the caudal vein before and 3 days after surgery. The distal one-half centimeter of the tail was clipped and a capillary pipette was used to collect two samples of $80 \mu \mathrm{L}$ each from the bleeding surface. Immediately after collection, the cut surface of the tail was cauterized with styptic powder. Serum cardiac troponin I (cTnl) was measured using the ADVIA Centaur ${ }^{\circledR}$ immunoassay (Bayer Diagnostics, Germany), which has a sensitivity and assay range of $0.1-50 \mathrm{ng} / \mathrm{mL}$. Serum creatine kinase isoenzyme $\mathrm{MB}$ (CK-MB) was measured by chemiluminescence immunoassay using the IMMULITE System (Diagnostic Products Corporation, Germany).

\section{Echocardiography}

We used an echocardiography color-system (GE vivid 7 Megas) equipped with a 12-MHz electronic-phased-array transducer at a rate of 100 frames/s. All images were acquired at a depth setting of $6 \mathrm{~mm}$ using direct chest contact. Under ketamine and xylazine anesthesia, the animal's chest was shaved and the animal was maintained either in left lateral decubitus or in the supine position. Subcutaneous electrodes were taped to the mice allowing ECG for observation of heart rate. Images were obtained from the left parasternal window. Short-axis 2-dimensional views of the left ventricle (LV) were taken at the level of the papillary muscles to obtain the M-mode recordings. Anterior and posterior end-diastolic and end-systolic wall thickness, LV, left atrium and aorta internal dimensions, and shortening fraction were measured according to the leading-edge method of the American Society of Echocardiography (ASE) (16). Transmitral and aortic flow pulsed Doppler measurements were acquired in the parasternal long-axis view. Mice were followed sequentially by comparing pre- and post-procedure measurements in the same animal. Normalization for anthropometric measures did not show significant differences. All post-infarction analyses were performed at 49 days after surgery by the same echocardiographist, who was blind to group allocation (sham-operated or MI).

\section{Evaluation of serum immunoglobulin (Ig) concentrations}

Briefly, 96-well flat-bottom plates were coated overnight at $4^{\circ} \mathrm{C}$ with $3 \mu \mathrm{g} / \mathrm{mL}$ purified goat anti-mouse $\operatorname{lgM}$ or IgG (Southern Biotech, USA), diluted in $50 \mathrm{mM}$ phosphate buffer, pH 8.0. After blocking nonspecific binding sites with $0.5 \%$ gelatin-PBS (Sigma Chemical Company, USA), serum samples were plated in serial dilutions and incubated for $2 \mathrm{~h}$ at $37^{\circ} \mathrm{C}$. Following extensive washing with $0.1 \%$ Tween 20 PBS, the plates were incubated with horseradish peroxidase-labeled goat anti-mouse IgM or IgG (Southern Biotech) for $1 \mathrm{~h}$ at $37^{\circ} \mathrm{C}$. After several washes in PBS-0.1\% 
Tween 20, the reaction was developed with 3,3',5,5'-tetramethyl benzidine substrate (Sigma). The enzymatic reaction was stopped with $\mathrm{H}_{2} \mathrm{SO}_{4}$ and the plates were read at 450 $\mathrm{nm}$ on a microplate spectrophotometer (SOFTmax Pro; Molecular Devices, USA). Unlabeled purified IgM and IgG (Southern Biotech) were used as standards. Serum IgM or IgG concentrations are reported as $\mu \mathrm{g} / \mathrm{mL}$.

\section{Assessment of serum anti-heart Ig repertoire}

Murine hearts (at least 5 hearts per group) were mechanically disrupted with a homogenizer (Polytron; Brinkmann Instruments, USA) with appropriate buffer (2\% SDS, 5\% 2-mercaptoethanol and $62.5 \mathrm{mM}$ Tris $/ \mathrm{HCl}, \mathrm{pH}$ 6.8 ) on ice, as described previously (17). The extract was sonicated at maximum power for 2 min and then boiled for $10 \mathrm{~min}$. The samples were cooled to $4^{\circ} \mathrm{C}$ and centrifuged, the supernatant was collected and filtered (5- $\mu \mathrm{m}$ pores), and protein concentration was measured by spectrophotometry at $280 / 260 \mathrm{~nm}$. Aliquots of heart extract were stored at $-80^{\circ} \mathrm{C}$ and defrosted only once, prior to use. Heart extract $(600 \mu \mathrm{g})$ was submitted to electrophoresis on $10 \%$ polyacrylamide gels under reducing conditions in a Mighty Small II SE 250 apparatus (Hoefer Scientific Instruments, USA). Proteins were transferred onto nitrocellulose membranes $(0.2 \mu \mathrm{m}$; Schleicher and Schull, Germany) using a Semi-Dry Electroblotter B (Ancos, Denmark) and blocked overnight with PBS-0.2\% Tween 20. Incubation of sera from infarcted, sham-operated and control mice $(50 \mu \mathrm{L}$ 1:20 dilution in PBS-0.2\% Tween 20) with the blotted membrane was performed using a 28-channel Miniblot System (Immunetics Inc., USA). After 4-h incubation at room temperature, the membranes were extensively washed and incubated with the secondary antibodies coupled to alkaline phosphatase specific for mouse IgM or IgG antibodies (Southern Biotech) for $90 \mathrm{~min}$. After washings, immunoreactivities were revealed with nitroblue tetrazolium/bromo-chloro-indolyl phosphate substrate (Promega, USA) in appropriate buffer (100 mM Tris/ $\mathrm{HCl}, \mathrm{pH}$ 9.5, $100 \mathrm{mM} \mathrm{NaCl}, 5 \mathrm{mM} \mathrm{MgCl}_{2}$ ) and the reaction was stopped after 3-5 min with distilled water. Immunoreactivities were quantified by optical scanning of the membranes in the reflective mode, followed by computer-based densitometry. Total protein profiles were acquired after staining of the blotted proteins with colloidal gold (Protogold), and then submitted to a second densitometric quantitation. Data analysis was done on Maclntosh computers (Apple Computer Inc., USA) with the IGOR software (Wavemetrics, USA) and special macros written for the analysis of Western blots. Protein and immunoreactivity profiles were superimposed after migration distortions were corrected to allow the semi-quantitative comparison of immunoreactivity by multivariate statistics - principal component analysis (PCA) (18).

\section{Cytokine analysis}

Blood samples were collected (from at least 5 animals per group) between 10:00 and 12:00 am 49 days after surgery as described for the myocardial damage markers. Blood was placed on ice and plasma was collected by centrifugation at $800 \mathrm{~g}$ for $15 \mathrm{~min}$ at $4^{\circ} \mathrm{C}$, aliquoted and stored at $-80^{\circ} \mathrm{C}$ until the day of analysis. AMultiplex cytokine kit [IFN- $\gamma$, TNF- $\alpha$, IL-1 $\beta$, IL-4, IL-6, KC (IL-8), IL-10, IL-12 (p40), MCP-1] was used and the assay performed according to manufacturer instructions (Bio-Rad, USA). Briefly, the appropriate cytokine standards and samples $(50 \mu \mathrm{L})$ diluted in plasma dilution buffer were added to the wells of a filtered plate. The samples were incubated with $50 \mu \mathrm{L}$ of the antibody-coupled microsphere set (2000 beads/well) at room temperature for $30 \mathrm{~min}$ on a plate shaker (set to 300 $\mathrm{rpm}$ ) in the dark and filter washed three times with $100 \mu \mathrm{L}$ wash buffer. Freshly diluted secondary/detection antibody (25 $\mu \mathrm{L} /$ well) was added to the wells and then incubated at room temperature on a plate shaker for $30 \mathrm{~min}$ in the dark and filter washed three times with $100-\mu \mathrm{L}$ wash buffer. Fifty microliters of streptavidin-phycoerythrin $(16 \mu \mathrm{g} / \mathrm{mL}$ in assay buffer) was added to the wells and incubation at room temperature continued for the first $10 \mathrm{~min}$ on a plate shaker. Unbound analytes were filtered through the wells using the vacuum manifold and the bound beads washed three times with 100- $\mu \mathrm{L}$ wash buffer. Following the last wash step, 125- $\mu \mathrm{L}$ assay buffer was added to each well and the plate placed for $1 \mathrm{~min}$ on a plate shaker set at 500 $\mathrm{rpm}$, followed by reduced speed to $300 \mathrm{rpm}$ for $3 \mathrm{~min}$. Fifty microliters of sample was analyzed on the Bio-Plex system (Bio-Rad) according to manufacturer instructions. Data analyses of all assays were performed with the Bio-Plex Manager software (19).

\section{Microarray analysis}

We compared RNA samples extracted from whole hearts of control $(N=4)$ and healed infarcted $(N=4)$ mice by analyzing hybridization to AECOM 32k mouse microarrays (https://www.ncbi.nlm.nih.gov/geo/query/acc. cgi?acc=GPL5371) spotted with Operon version 3.0 70mer oligonucleotides. The hybridization protocol, the slide type and the scanner settings were uniform throughout the entire experiment to minimize the technical noise. Thirty micrograms total RNA extracted in Trizol from each heart was reverse transcribed in the presence of fluorescentAlexa Fluor ${ }^{\circledR} 647-$ aha-dUTPs to obtain "red"-labeled cDNA. Eight samples, each consisting of $30 \mu \mathrm{g}$ total RNA, of our universal reference (20) prepared from 10 adult mouse tissues (aorta, brain, heart, kidney, liver, lung, ovary/testicle, spleen, and stomach - equal amounts from males and females) were reverse transcribed in the presence of fluorescent Alexa Fluor $^{\circledR}$ 555-aha-dUTPs to obtain "green"-labeled cDNA. On each microarray slide, co-hybridization of a red-labeled heart sample and a green-labeled reference sample was performed overnight at $50^{\circ} \mathrm{C}$. After washing $(0.1 \%$ SDS and $1 \%$ SSC) to remove the non-hybridized cDNAs, each array was scanned at $750 \mathrm{~V}(635 \mathrm{~nm})$ and $670 \mathrm{~V}(532 \mathrm{~nm})$ with 
an Axon 4000B dual-laser scanner. Locally corrupted and saturated spots, as well as those for which the foreground median fluorescence did not exceed double the median local background fluorescence on one slide, were eliminated from the analysis of all slides, with four independent measurements (in biological replicas) thus being obtained for each gene in each condition. Microarray data were processed as indicated in previous studies $(20,21)$. Thus, we used a normalization algorithm that alternated intra-chip and interchip normalization until the residual error was below $5 \%$ in subsequent steps. The spots probing the same gene were organized into redundancy groups to which we applied Bonferroni adjustment. Considering variance among the 4 control and $4 \mathrm{MI}$ hearts (using the Student heteroscedastic $t$-test of equality of the means of the distributions with a Bonferroni-type adjustment), all target genes that showed statistically significant $(P<0.05)$ changes of at least 1.5 -fold were considered to be differentially expressed. GenMapp (22) and MappFinder softwares (www.genmapp.org) (23) and databases were used to identify the most affected Gene Ontology categories.

\section{Real-time RT-PCR}

The level of mRNA expression of control $(N=4)$ and infarcted $(\mathrm{N}=4)$ mouse hearts was measured by real-time RT-PCR (qRT-PCR) to validate the microarray experiment. Genes involved in the inflammatory response, Hif1a, Ifnar1, Nos2, Mmp23, and TIr4, were chosen. The same total RNA preparation was used in the microarray and real-time experiments. The cDNA was prepared using a High Capacity cDNA Reverse Transcription kit (Applied Biosystems, USA) following manufacturer instructions. The forward and reverse primer sequences used in the qRT-PCR assay are listed below. qRT-PCR amplifications were performed in a 96-well plate of the ABI Prism 7500 Fast Sequence Detector (Applied Biosystems) in a reaction mixture of $25 \mu \mathrm{L}$, which contained $1 \mu \mathrm{L}$ 100X diluted cDNA, $12.5 \mu \mathrm{L} 2 \mathrm{X}$ Power SYBR Master Mix (Applied Biosystems) and $150 \mathrm{nM}$ of each primer. Actb (Gene bank accession number NC_000071): Forward (5'-3') CATCACTATTggCAACgAgCg, Reverse (5'-3') ATGGATGCCACAGGATTCCA. Hif1a (Gene bank accession number NM_010431): Forward (5'-3') TCAAgTC AgCAACgTggAAg, Reverse (5'-3') TATCgAggCTgTgTCg ACTg. Ifnar1 (Gene bank accession number NC_000082): Forward (5'-3') TCCCCgCAgTATTgATgAgT, Reverse (5'-3') CTggTCTgTgAgCTgTACTT. Mmp23 (Gene bank accession number NC_00070.5): Forward (5'-3') CCAC GGTGGCATTCACTTTGATGA, Reverse (5'-3') CAATg TggCATTgAggTgCATgAg. Nos2 (Gene bank accession number NM_010927): Forward (5'-3') TCCCTgATgACATT CCTTCTT, Reverse (5'-3') CATTggAAgTgAAgCgTTTCg. TIr4 (Gene bank accession number NM_021297): Forward (5'-3') CAgCTgggCTgTACAAACCTT, Reverse (5'-3') TgAg CCACATTgAgTTTCTTTA.

The amplification program was $55^{\circ} \mathrm{C}$ for $2 \mathrm{~min}, 95^{\circ} \mathrm{C}$ for $10 \mathrm{~min}$, followed by 40 cycles at $95^{\circ} \mathrm{C}$ for $15 \mathrm{~s}$ and annealing at $60^{\circ} \mathrm{C}$ for $1 \mathrm{~min}$. The qRT-PCR melting curve data were collected to check PCR specificity. Each cDNA sample was tested in triplicate, and a corresponding nonreverse transcriptase reaction was included as a control for DNA contamination. In addition, the expression of the chosen genes was normalized to that of $\beta$-actin as an internal control.

The relative quantities of gene-specific mRNA expression were determined by the comparative CT method expressed by the formula $2-(\Delta \mathrm{Ct})$ where $\mathrm{Ct}$ refers to the "threshold cycle" and is determined for each plate with 7500 real-time PCR System Sequence Detection Software (Applied Biosystems). $\Delta \mathrm{Ct}$ is the difference between the $\mathrm{Ct}$ of the target mRNA and the Ct of the endogenous control $(\beta$-actin). The fold-change in the expression of the target genes in response to the infarct was calculated as follows: mean $\pm \mathrm{SD}$ of $2-(\Delta \mathrm{Ct})$ for each group followed by the determination of the ratio between infarcted and normal.

\section{Statistical analysis}

Animals were divided into three experimental groups: non-operated control $(N=25)$, sham-operated $(N=7)$, and infarcted mice $(\mathrm{N}=30)$. All groups were analyzed together by investigators blind to which animals were sham-operated or infarcted. All data are reported as means \pm SD. Differences between the values obtained for control, sham-operated and infarcted groups were evaluated by one-way analysis of variance (ANOVA) followed by the Bonferroni post-test. Nonparametric variables were evaluated by the KruskalWallis test and the Dunn post-test. Statistical significance was defined by $\mathrm{P}<0.05$.

\section{Results}

Myocardial infarction and assessment of heart failure

Surgical mortality was $23 \%(7 / 30)$ and during the first 2 weeks post-infarction $43 \%$ (10/23) of the animals died, with no further death until the end of the study at 7 weeks. No sham-operated mice $(\mathrm{N}=7)$ died during the same period. Interruption of left anterior coronary perfusion led to the development of ST-segment elevation and " $Q$ " waves after $24 \mathrm{~h}$ (data not shown). Infarcted mice also developed atrial and ventricular conduction alterations such as widened $P$, QRS complex and longer rate-corrected QT intervals (Table 1). Myocardial infarction was confirmed by CK-MB and cTnl levels (data not shown), which showed a significant increase 3 days after surgery compared to sham-operated and control groups $(P<0.001)$. cTnl levels $\left(>0.3 \mathrm{ng} / \mathrm{mm}^{3}\right)$ were increased in $95 \%$ of these animals. No sham-operated animal had a cTnl concentration above $0.3 \mathrm{ng} / \mathrm{mm}^{3}$ after surgery.

There was a significant impairment of global LV function measured 7 weeks after MI (Table 2). The shortening fraction decreased from 36 to $22 \%(P<0.05)$ and diastolic LV diameters increased by $11 \%$. A representative M-mode image 
of the LV of an MI mouse (Figure 1B) shows anterior wall thinning associated with hypokinesia when compared with sham-operated and control groups and with the posterior intact wall. The HF group developed diastolic dysfunction confirmed by an elevated E/A ratio (4.51 \pm 1.09 for HF vs $3.25 \pm 0.78$ for control animals). There was no significant difference in heart rate (HR) under a ketamine/xylazine anesthesia regimen (Table 2). Myocardial infarction sizes were about 20 to $30 \%$ of the LV in the chronic state (data not shown). During sacrifice the majority of infarcted mice exhibited pleural effusion consistent with HF.

\section{Post-ischemic heart failure results in a sustained increase in serum IgM and IgG reactivities directed at heart auto-antigens}

Sera of post-ischemic HF mice were analyzed for total IgM and IgG levels by quantitative ELISA. While non-manipulated or shamoperated mice presented comparable levels of both IgM (Figure 2A) and IgG (Figure 2B), a dramatic increase in both immunoglobulin isotypes was identified in the serum of infarcted mice 7 weeks later. To evaluate the impact of post-ischemic HF on the serum levels of antiheart reactive antibodies we applied a semiquantitative immunoblot technique. When serum IgM and IgG from individual mice were assayed for reactivity against syngeneic heart extracts we observed that the reactive patterns were similar in all animals of the same experimental group. As expected, both control and shamoperated mice exhibited comparable anti-heart serum IgM or IgG repertoires, characterized by a natural antibody repertoire weakly reactive to heart antigens. In contrast, mice submitted to experimental post-ischemic HF exhibited remarkably higher levels of anti-heart reactive IgM and lgG in their sera 7 weeks after surgical intervention (Figure 3).

Western blot densitometry profiles displayed extensive increases in the anti-heart profiles of both IgM and IgG reactivities. This alteration reflects not only the enhancement of existing natural antibody specificities, but also the emergence of new IgM and IgG anti-heart specificities in the serum of HF mice (Figure 3). When the scores obtained from densitometry profiles of anti-heart reactivity were subdivided taking into account individual reactivity for each mouse from control and HF groups and submitted to a classical multivariate statistical treatment, i.e., PCA, the differences between these groups were prominent. The first two principal components of both IgM and IgG reactivities clearly segre- gated HF and control mice into non-overlapping areas of the two-dimensional space defined by the first two PCA factors. These principal components are related to the impressive increase of serum IgM and IgG specificities for heart antigens occurring and persisting after the establishment of HF (Figure 3B, inset). There were no significant differences between control and sham-operated groups (data not shown).

Table 1. Electrocardiographic analysis of C57BL/6 mice.

\begin{tabular}{lccc}
\hline & $\begin{array}{c}\text { Control } \\
(\mathrm{N}=25)\end{array}$ & $\begin{array}{c}\text { Sham-operated } \\
(\mathrm{N}=7)\end{array}$ & $\begin{array}{c}\text { Myocardial infarction } \\
(\mathrm{N}=10)\end{array}$ \\
\hline Heart rate $(\mathrm{bpm})$ & $592 \pm 105$ & $679 \pm 80$ & $532 \pm 78^{+}$ \\
Amplitude & & & \\
P wave $(\mathrm{mV})$ & $0.088 \pm 0.033$ & $0.118 \pm 0.036$ & $0.147 \pm 0.068$ \\
Q wave (mV) & $0.003 \pm 0.014$ & $0.031 \pm 0.045$ & $0.221 \pm 0.276^{*+}$ \\
QRS complex (mV) & $0.608 \pm 0.254$ & $0.760 \pm 0.392$ & $0.357 \pm 0.316^{+}$ \\
ST segment (mV) & $0.004 \pm 0.003$ & $0.084 \pm 0.087$ & $0.397 \pm 0.363^{*+}$ \\
T wave (mV) & $0.106 \pm 0.063$ & $-0.024 \pm 0.200$ & $-0.140 \pm 0.270^{*}$ \\
Duration & & & \\
P wave (ms) & $11 \pm 2$ & $12 \pm 1$ & $14 \pm 2^{*}$ \\
PR interval (ms) & $34 \pm 7$ & $32 \pm 5$ & $37 \pm 6$ \\
QRS (ms) & $11 \pm 2$ & $14 \pm 3$ & $15 \pm 2^{*}$ \\
QT interval (ms) & $22 \pm 6$ & $39 \pm 13$ & $68 \pm 49^{*+}$ \\
QTc & $71 \pm 13$ & $177 \pm 147$ & $201 \pm 143^{*}$ \\
\hline
\end{tabular}

Data are reported as means \pm SD. QTC $=$ QT corrected interval. ${ }^{*} \mathrm{P}<0.05$ vs control; ${ }^{+} \mathrm{P}<0.05$ vs sham-operated (one-way ANOVA).

Table 2. Echocardiographic analysis of mice with myocardial infarction.

\begin{tabular}{lccc}
\hline & $\begin{array}{c}\text { Control } \\
(\mathrm{N}=25)\end{array}$ & $\begin{array}{c}\text { Sham-operated } \\
(\mathrm{N}=7)\end{array}$ & $\begin{array}{c}\text { Myocardial infarction } \\
(\mathrm{N}=10)\end{array}$ \\
\hline Heart rate $(\mathrm{bpm})$ & $250 \pm 31$ & $298 \pm 56$ & $249 \pm 41$ \\
Flux & & & \\
Peak A (m/s) & $0.14 \pm 0.05$ & $0.12 \pm 0.02$ & $0.13 \pm 0.02$ \\
Peak E (m/s) & $0.43 \pm 0.09$ & $0.39 \pm 0.07$ & $0.53 \pm 0.13^{*+}$ \\
E/A & $3.25 \pm 0.78$ & $3.29 \pm 0.67$ & $4.51 \pm 1.09^{*+}$ \\
Mct (ms) & $158 \pm 43$ & $96 \pm 43$ & $149 \pm 68$ \\
Ajt (ms) & $94 \pm 18$ & $90 \pm 22$ & $80 \pm 7^{*}$ \\
Diameters & & & \\
Awthd (cm) & $0.08 \pm 0.01$ & $0.09 \pm 0.02$ & $0.06 \pm 0.01^{*+}$ \\
Pwthd (cm) & $0.09 \pm 0.01$ & $0.11 \pm 0.03$ & $0.08 \pm 0.04^{+}$ \\
LVDd $(\mathrm{cm})$ & $0.36 \pm 0.03$ & $0.32 \pm 0.11$ & $0.40 \pm 0.05^{*+}$ \\
LVDs $(\mathrm{cm})$ & $0.23 \pm 0.03$ & $0.21 \pm 0.11$ & $0.32 \pm 0.05^{*+}$ \\
FS $(\%)$ & $36 \pm 6$ & $37 \pm 12$ & $22 \pm 7^{*+}$ \\
\hline
\end{tabular}

Data are reported as means $\pm S D$. $A=$ transmitral late filling velocity; $E=$ transmitral early filling velocity; $\mathrm{Mct}=$ mitral closure time; $\mathrm{Ajt}=$ aortic ejection time; Awthd = diastolic anterior wall thickness; Pwthd = diastolic posterior wall thickness; LVDd = diastolic left ventricle (LV) dimension; LVDs = systolic LV dimension; FS\% = fractional shortening. ${ }^{*} \mathrm{P}<0.05 \mathrm{vs}$ control; ${ }^{+} \mathrm{P}<0.05 \mathrm{vs}$ sham-operated (one-way ANOVA). 


\section{Effect of ischemic heart failure on circulating cytokine profile}

In an independent time course experiment, we observed a slight but significant increase in plasma concentrations of all cytokines tested shortly after MI or sham surgery (data not shown), reflecting alterations induced by the surgical procedures. When the assessment was performed 7 weeks post-surgery we observed that most cytokines had returned to control levels in the sham-operated group. One exception was IL-12, which showed persistent elevation in the serum of the sham-operated mice even after 7 weeks. In contrast, post-ischemic HF mice exhibited persistently elevated levels of circulating cytokines (Figure 4$)$. IL-1 $\beta(P=0.033)$ and TNF- $\alpha(P=0.004)$, pro-inflammatory cytokines, were significantly higher in plasma 7 weeks after MI compared to control. Moreover, INF- $y$, a typical Th1 response mediator, was higher $(P=0.031)$ in the $\mathrm{Ml}$ group than in the other groups. In contrast, the anti-inflammatory cytokines IL-4 (P = $0.17)$ and IL-10 ( $P=0.19)$ did not differ significantly among groups (Figure 4B). Importantly, a highly significant increase was observed in the plasma levels of the chemokines $\mathrm{KC}$ (IL-8 murine ortholog) $(\mathrm{P}=0.008)$ and MCP-1 (Ccl2; $\mathrm{P}=$ 0.018 ) in the infarcted group compared to control.

\section{Differential gene expression profile in post-ischemic heart failure mouse hearts}

Whole heart tissues from HF (7 weeks post-MI) or control mice were sampled to examine changes in gene expression associated with the disease. The experiment was performed according to Minimum Information about a Microarray Experiment (MIAME) standards and the results were deposited in http://www.ncbi.nlm.nih.gov/sites/ entrez?db=geo as series GSE18703. A total of 14,755 distinct genes with known protein products were probed
A

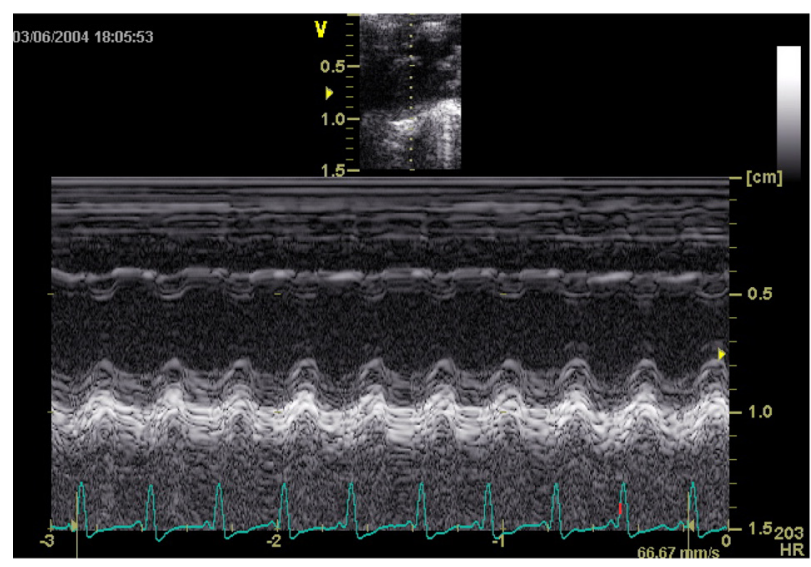

B

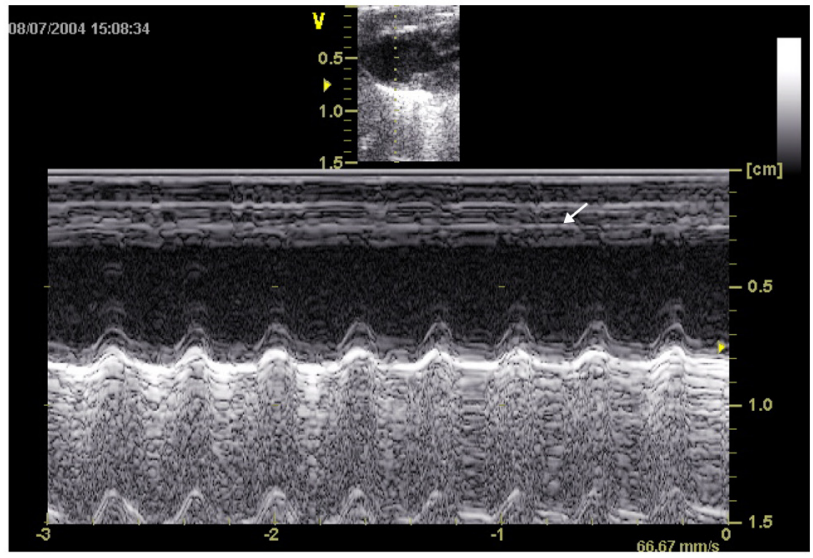

Figure 1. M-mode echocardiography. Representative parasternal short axis views 3 weeks after surgery of sham-operated (A) and infarcted (B) mice. Observe the wall thinning and decrease in anterior wall motion (arrow) in the infarcted mouse.

A

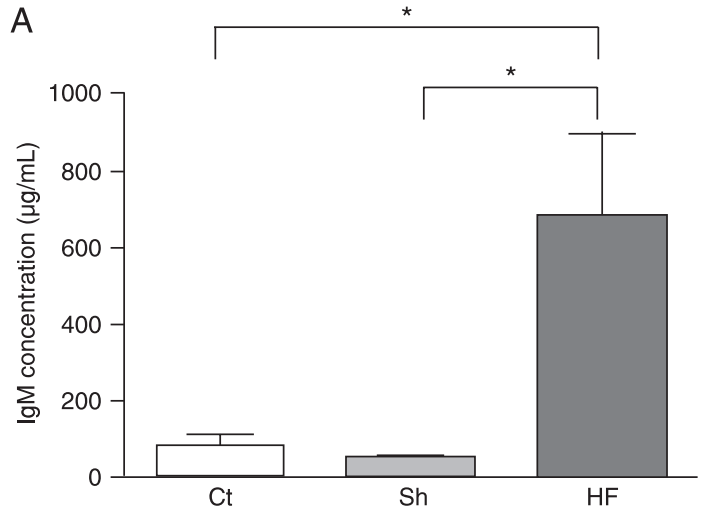

B

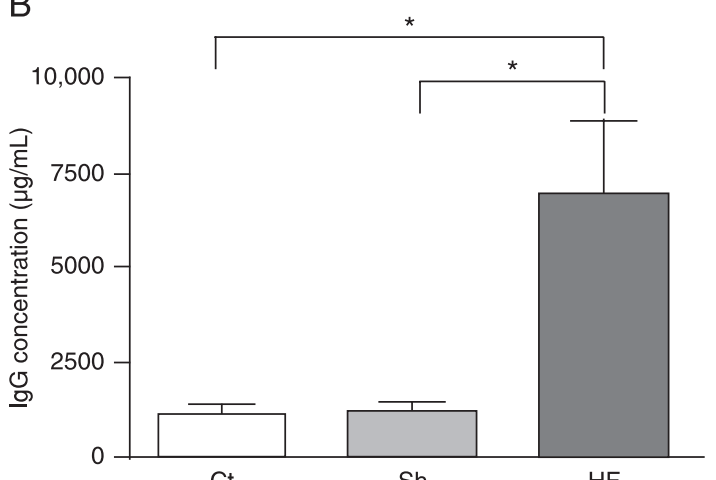

Figure 2. Increased levels of serum IgM and IgG in mice with post-ischemic heart failure. Serum $\lg M(A)$ and $\lg G(B)$ concentrations in post-ischemic heart failure (HF) or sham-operated (Sh) mice were tested by ELISA 7 weeks after surgery. Data for non-manipulated age-matched control C57BL/10 mice are also presented (Ct). Data are reported as means \pm SD for at least 5 mice per group. ${ }^{*}<<$ 0.0001 , HF mice vs Ct and Sh mice (Kruskal-Wallis test). 
in this experiment. Of these, $1989(13.48 \%)$ were significantly up-regulated and $90(0.61 \%)$ were down-regulated in post-ischemic HF hearts. Using the GenMapp software to categorize Gene Ontology terms, we examined whether certain cellular pathways encoded by altered genes were prominently affected in the infarcted myocardium. Downregulated genes predominantly represented G-protein signaling, cell communication, respiratory chain complex IV, regulation of secretion, $z$ disc, sarcomere and sarcoplasmic reticulum, gluconeogenesis, and voltage gated chloride channel gene products. Up-regulated genes predominantly encoded molecules involved in complement activation, immune response, protein degradation (cysteine-type and ubiquitin protease as well as aminopeptidase activity, modification-dependent protein catabolism), tumor necrosis factor binding, $\mathrm{Ca}^{2+}$ transport, $\beta$-catenin binding, cytoskeleton organization, and biogenesis gene products. Known genes were sorted on the basis of their functions such as immune and inflammatory response, apoptosis, cell proliferation and differentiation. We validated by real-time PCR five of the genes that were found by the microarray analysis to be either up- (Hif1a, Ifnar1, Mmp23, and TIr4) or not regulated (Nos2). These results, which quantitatively agreed with those of the microarray analysis, are illustrated in Figure 5.
A

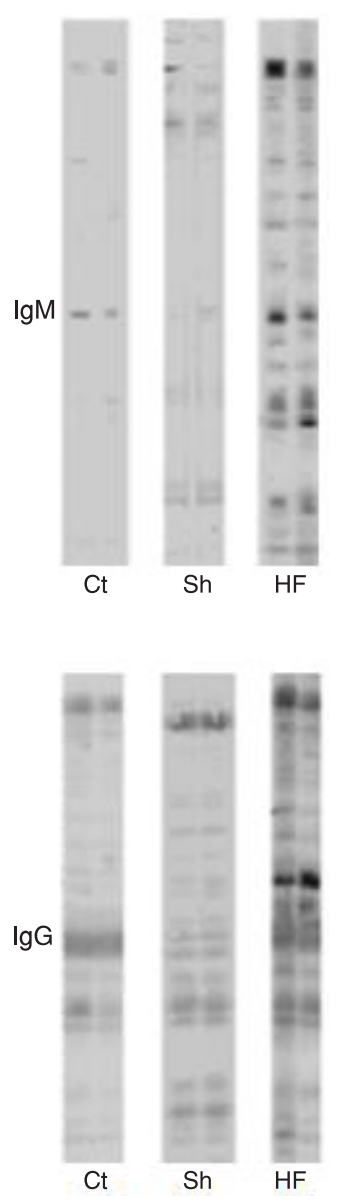

B

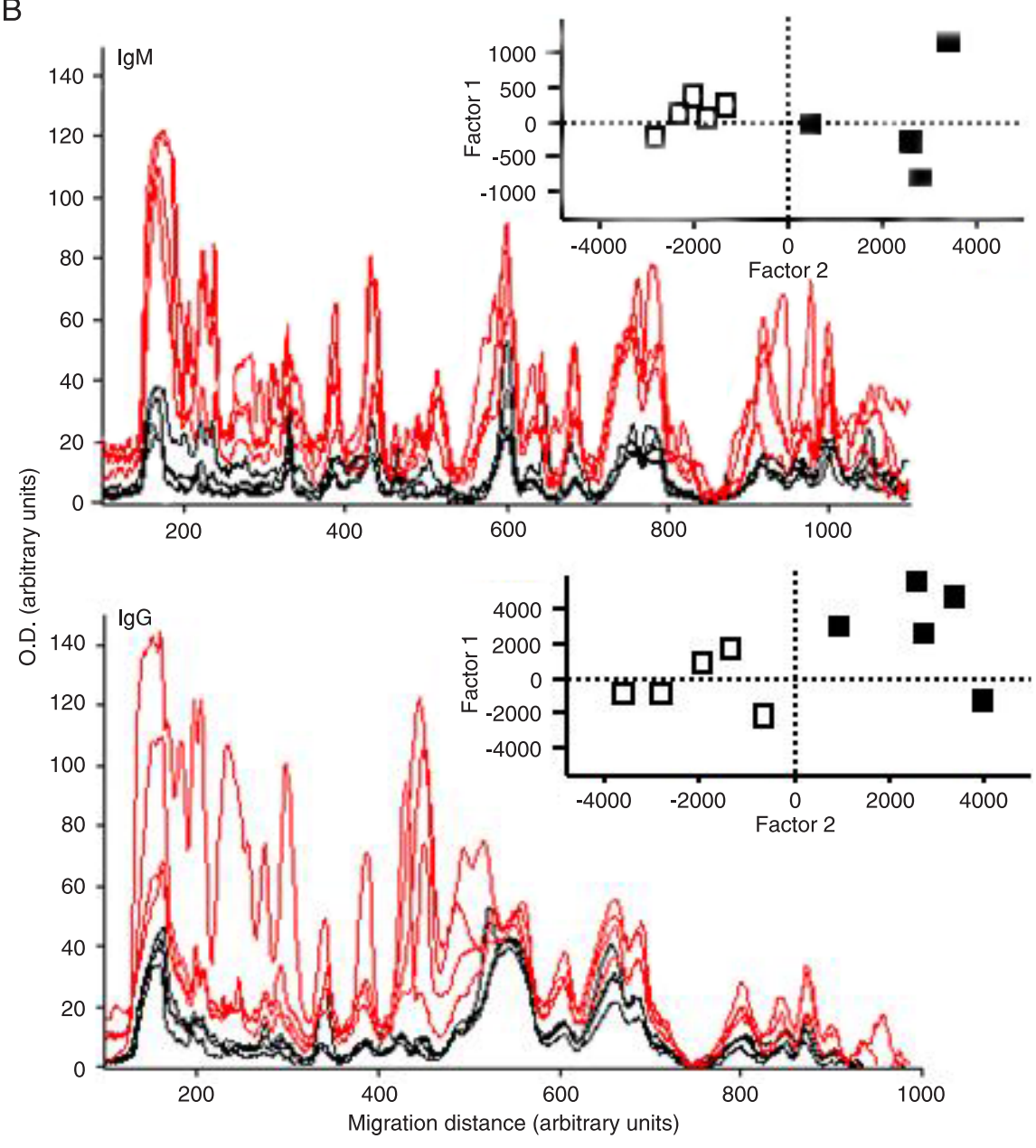

Figure 3. Increased anti-heart antibodies in mice with post-ischemic heart failure. $A$, Semi-quantitative immunoblot of IgM and IgG reactivity to autologous heart extract was scored for individual control (Ct), sham-operated (Sh) and heart failure (HF) mice 7 weeks after surgery. B, Densitometric profiles of serum IgM and IgG immunoreactivities of individual control (black lines) and HF (red lines) mice to heart extracts are shown. Reactivity intensities (absorbance) and migration distances are reported as arbitrary units. The values of the individual IgM or IgG immunoreactivity intensity (peak value) were submitted to principal component analysis. Scores of the resulting first two principal components of the individual $\mathrm{Ct}$ and HF mice are shown in two-dimensional plots in the insets: control (open squares) and heart failure mice (black squares). Data are reported as means \pm SD of at least 5 mice per group. P $<0.05, \mathrm{HF}$ mice vs control mice (Kruskal-Wallis test). 

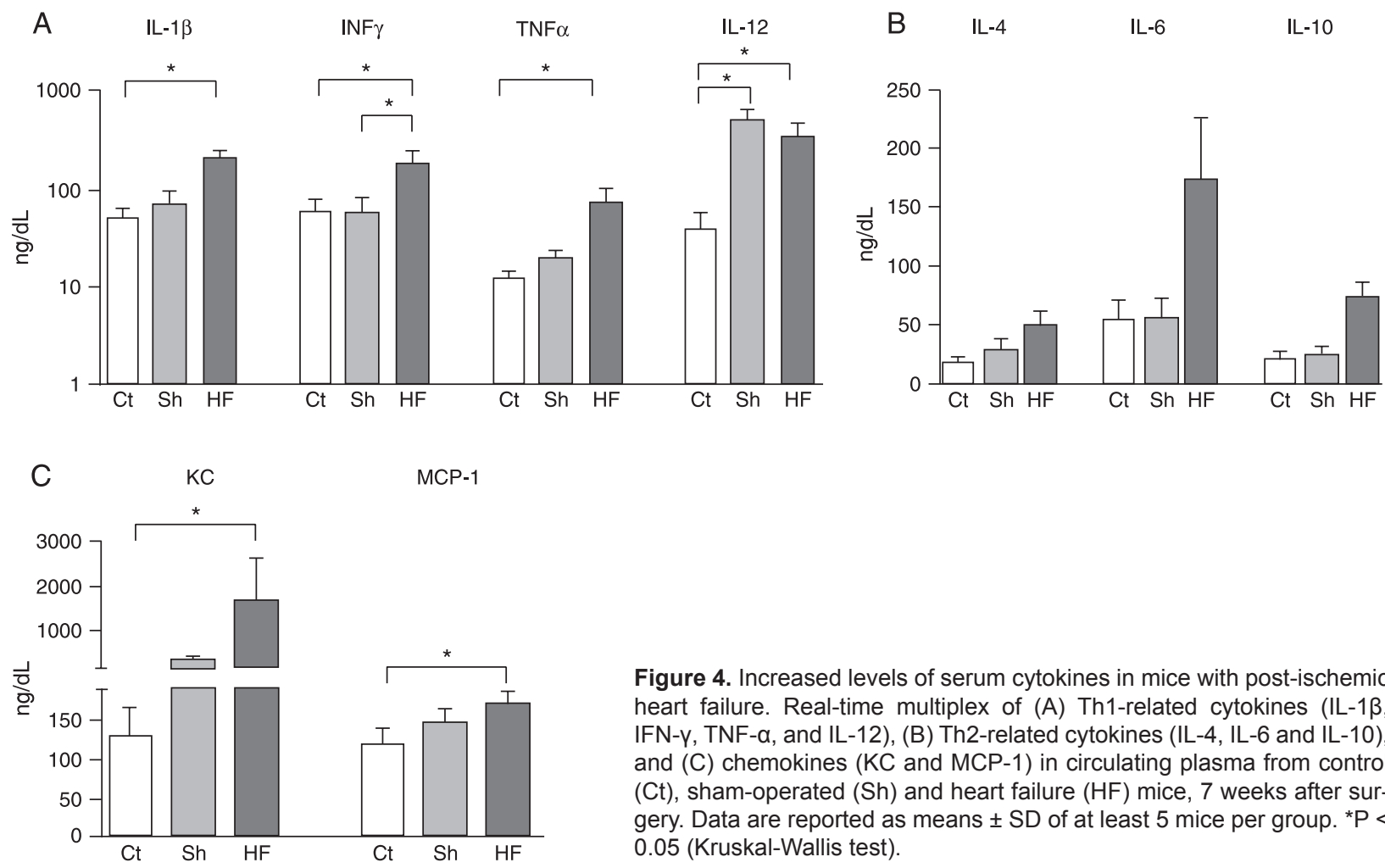

Figure 4. Increased levels of serum cytokines in mice with post-ischemic heart failure. Real-time multiplex of (A) Th1-related cytokines (IL-1 $\beta$, IFN-y, TNF- $\alpha$, and IL-12), (B) Th2-related cytokines (IL-4, IL-6 and IL-10), and $(C)$ chemokines (KC and MCP-1) in circulating plasma from control (Ct), sham-operated (Sh) and heart failure (HF) mice, 7 weeks after surgery. Data are reported as means $\pm S D$ of at least 5 mice per group. ${ }^{*} \mathrm{P}<$ 0.05 (Kruskal-Wallis test).

\section{Gene expression patterns indicative of an immune inflammatory response}

A specific objective of this study was to identify late changes in myocardial transcription of immune-mediated inflammatory response genes after the establishment of post-ischemic HF. Of the 184 quantified genes known to be related to the inflammatory/immune/defense response (see Table 3 and Supplementary Tables $1 \mathrm{~A}$ and $1 \mathrm{~B}$ for all quantified genes in this category), we found that 38 (20.7\%; Table 3) were significantly $(>1.5$-fold, $\mathrm{P}<0.05)$ up-regulated after chronic MI. In addition, 37 other genes had a change exceeding 1.5-fold but increases were not significant $(P$ $>0.05$; see Supplementary Table $1 \mathrm{~A}$ ), so that $41 \%$ of all sampled genes related to the inflammatory/immune/defense response showed $>1.5$-fold up-regulation. Among the significantly up-regulated genes there were 3 chemokines (Ccl8, Ccl9, and Cxcl14) and a chemokine-like receptor, 3 interferon receptors (Ifnar1, Ifngr1, Ifngr2), 6 interferon activated genes (Ifi204, Ifi205, Isg20, Icsbp1, Ifih1, Ifi1), 2 interleukins (II13, II1f9), 4 interleukin receptors (II1r1, II13ra1, II2rg, II22ra1), 4 interleukin-1 receptor-associated kinases (Irak1, Irak2, Irak3, Irak4), and 7 tumor necrosis factor receptors (Tnfrsf1a, Tnfrsf1b, Tnfrsf10b, Tnfrsf12a, Tnfrsf19l, Tnfrsf22, Tnfrsf25). As expected, no inflammationrelated gene was found to be significantly down-regulated, although the change in the expression of 5 (i.e., $<3 \%$ ) of them (Cklfsf2a, Cxcl12, II17e, II17f, Tnfsf15) exceeded 1.5- fold. The fact that several cytokine and chemokine genes were transcriptionally elevated indicates pro-inflammatory properties within chronically injured myocardial tissue.

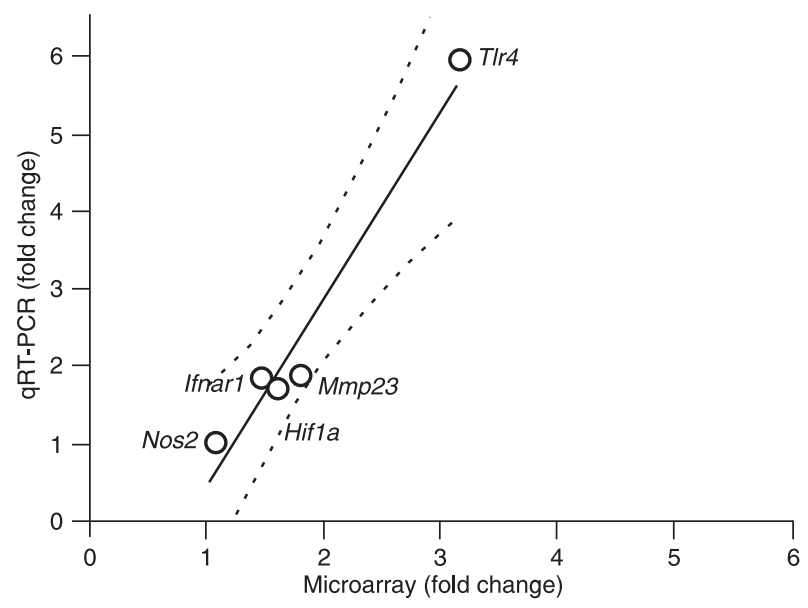

Figure 5. Real-time PCR validation of changes in the expression of five genes that were found to be altered in microarray analysis (Hif1a, Ifnar1, Mmp23, Nos2, and TIr4). Fold changes for each gene indicate that expression changes determined by each method are positively correlated for these sampled genes. Linear regression curve with dotted line as $95 \%$ confidence interval (Pearson $R=0.968, P=0.0066)$. 
Table 3. Significant regulation of genes involved in the inflammatory/immune defense response of infarcted mice.

\begin{tabular}{|c|c|c|c|}
\hline Name & Symbol & $\mathrm{x}$ & $P$ \\
\hline Chemokine (c-c motif) ligand 8 & $\mathrm{Ccl} 8$ & 9.70 & 0.024 \\
\hline Chemokine (c-c motif) ligand 9 & Ccl9 & 2.31 & 0.040 \\
\hline Chemokine (c-x-c motif) ligand 14 & Cxcl14 & 2.31 & 0.027 \\
\hline Chemokine-like receptor 1 & Cmklr1 & 1.82 & 0.004 \\
\hline Complement component 3 & $\mathrm{C} 3$ & 2.68 & 0.015 \\
\hline Gamma-glutamyltransferase-like activity 1 & Ggtla1 & 2.16 & 0.026 \\
\hline Immunity-related gtpase family, m & Irgm & 1.81 & 0.009 \\
\hline Interferon (alpha and beta) receptor 1 & Ifnar1 & 1.51 & 0.016 \\
\hline Interferon activated gene 204 & Ifi204 & 3.21 & 0.000 \\
\hline Interferon activated gene 205 & Ifi205 & 5.06 & 0.001 \\
\hline Interferon consensus sequence binding protein 1 & Icsbp1 & 1.55 & 0.025 \\
\hline Interferon gamma receptor 1 & Ifngr1 & 2.02 & 0.013 \\
\hline Interferon gamma receptor 2 & Ifngr2 & 2.01 & 0.015 \\
\hline Interferon induced with helicase $\mathrm{c}$ domain 1 & Ifih1 & 1.58 & 0.006 \\
\hline Interferon-induced protein 35 & Ifi35 & 1.54 & 0.039 \\
\hline Interferon-stimulated protein & Isg20 & 1.58 & 0.012 \\
\hline Interleukin 1 family, member 9 & II1f9 & 1.69 & 0.018 \\
\hline Interleukin 1 receptor, type 1 & $\| 1 \mathrm{r} 1$ & 2.53 & 0.024 \\
\hline Interleukin 13 & $\| 13$ & 2.11 & 0.017 \\
\hline Interleukin 13 receptor, alpha 1 & II13ra1 & 1.93 & 0.005 \\
\hline Interleukin 2 receptor, gamma chain & $\| 2 \mathrm{rg}$ & 1.91 & 0.047 \\
\hline Interleukin 22 receptor, alpha 1 & II22ra1 & 2.17 & 0.047 \\
\hline Interleukin 6 signal transducer & $116 s t$ & 2.71 & 0.018 \\
\hline Interleukin-1 receptor-associated kinase 1 & Irak1 & 1.57 & 0.038 \\
\hline Interleukin-1 receptor-associated kinase 2 & Irak2 & 3.27 & 0.000 \\
\hline Interleukin-1 receptor-associated kinase 3 & Irak3 & 2.95 & 0.030 \\
\hline Interleukin-1 receptor-associated kinase 4 & Irak4 & 1.61 & 0.015 \\
\hline Nuclear factor of activated t-cells, cytoplasmic, calcineurin-dependent 4 & Nfatc4 & 1.94 & 0.015 \\
\hline Toll interacting protein & Tollip & 1.50 & 0.048 \\
\hline Toll-like receptor 2 & TIr2 & 1.65 & 0.005 \\
\hline Toll-like receptor 4 & TIr4 & 3.15 & 0.001 \\
\hline Tumor necrosis factor receptor superfamily, member $10 \mathrm{~b}$ & Tnfrsf10b & 1.68 & 0.043 \\
\hline Tumor necrosis factor receptor superfamily, member $12 a$ & Tnfrsf12a & 2.37 & 0.001 \\
\hline Tumor necrosis factor receptor superfamily, member 19 -like & Tnfrsf19l & 1.61 & 0.010 \\
\hline Tumor necrosis factor receptor superfamily, member $1 \mathrm{a}$ & Tnfrsf1a & 1.52 & 0.008 \\
\hline Tumor necrosis factor receptor superfamily, member $1 \mathrm{~b}$ & Tnfrsf1b & 1.92 & 0.006 \\
\hline Tumor necrosis factor receptor superfamily, member 22 & Tnfrsf22 & 1.80 & 0.039 \\
\hline Tumor necrosis factor receptor superfamily, member 25 & Tnfrsf25 & 1.80 & 0.025 \\
\hline
\end{tabular}

$X=$ fold difference (negative for down-regulation). The Student heteroscedastic $t$-test was used for the comparison of heart failure with control.

The majority of receptor genes regulated after chronic MI were related to TNF- $\alpha$, which has a critical role in diverse cellular events, including cell proliferation, differentiation and apoptosis. In agreement with systemic measurements of protein levels, we did not observe transcriptional regulation of expression of IL-4, IL-6 or IL-10 or their receptors in cardiac tissue 7 weeks after MI. In contrast, other in- terleukin and interleukin receptors and Toll-like receptors were up-regulated in the post-ischemic healed heart tissue. We also identified a significant up-regulation of $\operatorname{lgG}$ Fc receptor (FcgR3), related to antibody-dependent cellular cytotoxicity $(x=2.70, P=0.02)$. In addition, chemokine monocyte chemo-attractant protein (Ccl8), also known as monocyte chemo-attractant protein-2 (MCP-2), was highly 
expressed in the post-ischemic heart tissue, achieving a 9.7-fold increase (Table 3).

\section{Discussion}

After myocardial necrosis, sequestered cardiac antigens are exposed and presented to the immune system. This triggers both cellular and humoral immune responses consisting of activation of cytotoxic T cells and production of anti-heart antibodies (5,24-26). We report here that C57BL/6 mice submitted to Ml surgery presented remarkably higher levels of circulating IgMs and IgGs with increased auto-reactivity towards heart proteins, which persisted during the chronic stage of the disease. In acute MI, various proteins have been identified as targets of antibodies, including myosin (27), troponin I (16) and actin (28).

We report that a broad array of anti-heart antibody specificities are increased in the serum of post-ischemic HF mice. Our data suggest that cardiac-specific antigens may trigger the expansion and differentiation of disease-related auto-reactive $B$ cells, which are still active even after the healing process has occurred. However, the relationship between the specificity of the secreted antibodies and the outcome of heart disease remains to be determined. Remarkably, the increased expression of FcgR3 genes in the healed heart was also identified. This suggests an active function of antibodies mediating myocyte destruction by cytotoxicity and/or apoptosis, even 7 weeks after MI.

Sensitization to heart antigens after acute MI can be correlated with the increase in plasma cytokines and chemokines. These alterations can play an active role in the initiation, progression and maintenance of inflammatory responses by promoting cell activation and influx into the injured tissue, which lead to myocardial dysfunction (29). We demonstrated that persistently increased levels of circulating cytokines/ chemokines course with concomitant up-regulation of cardiac genes encoding cytokine/chemokine receptors after the establishment of post-ischemic HF. The imbalance between pro- and anti-inflammatory cytokines may determine the outcome of the healing and cardiac remodeling after acute MI. Pro-inflammatory cytokines such as IL-1 and TNF- $\alpha$ are increased in plasma after AMI (12) and we have now shown that these cytokines remain elevated even 7 weeks after MI when HF has developed. At first, these cytokines are determinant for the healing process and restoration of cardiac function through activation of matrix metalloproteinases, inhibition of collagen formation, and promotion of cell differentiation (30). However, these cytokines can also promote unfavorable events leading to chronic dilation, and finally lethal HF (14). The increase in serum INF- $y$ and its cardiac receptor gene suggests that the Th1 response plays a significant role in the evolution of HF. Anti-inflammatory cytokines such as IL10 and TGF- $\beta$ would provide the counter-activation signals restricting the excessive inflammatory response. In our study, however, cardiac gene expression of these cytokines did not show significant differences among the experimental groups. Indeed, altered expression of either anti-inflammatory cytokines or their receptor genes could not be detected in the heart after MI.

The evaluation of cardiac gene expression profile in response to myocardial ischemic dysfunction highlighted the activation of damage-repair and remodeling processes, as reflected by overexpression of several heat shock protein and Toll-like receptor-related genes. In addition, our analysis revealed an increase of pro-apoptotic signaling-related genes in the healed infarcted heart in agreement with published data (31). Thus, the response to chronic ischemic insult is associated with altered repair and remodeling processes, metabolic reprogramming and enhanced apoptosis, as previously observed by others in acute MI (32).

Furthermore, we showed that immune/inflammatory process-related gene receptors are up-regulated in the chronic infarction model, emphasizing that remodeling leading to HF is accompanied by alterations in immunemediated processes. The importance of immune-mediated inflammation in heart disease has been demonstrated in cardiotropic viral infections, immunization with cardiac antigens or exposure to other pathogens. Under these circumstances, cardiomyocyte injury occurs leading to cardiomyopathy, with the concomitant development of cardiac antibodies and cytotoxic T cell mediators (33-36), which are independent predictors of fatal cardiac events (37). In the present study, we demonstrated that in postischemic heart failure changes in the expression of cardiac genes occur along with robust and persistent cytokine and antibody systemic responses.

Although the observed alterations have been associated with cardiac impairment in the setting of acute MI, our results suggest that persistence of the systemic and local pro-immune/inflammatory repertoire may be important for the development of post-ischemic heart failure. Future experiments involving knockout mice are expected to reveal a more mechanistic view of the involvement of these immune/ inflammatory processes in the cardiac remodeling leading to heart failure after ischemia.

\section{Acknowledgments}

This study is part of the MD-PhD Program of the Federal University of Rio de Janeiro. The authors are grateful to Edson Rondinelli (IBCCF, Universidade Federal do Rio de Janeiro, Rio de Janeiro, RJ, Brazil) for discussing qRT-PCR experiments, to Roberto Esporcatte (Hospital Pró-Cardíaco) for helpful comments after reading the manuscript, and to Debora Ornellas (Universidade Federal do Rio de Janeiro) and Marcia Urban Maldonado (Albert Einstein College of Medicine) for excellent technical support. Research supported by grants from FAPERJ, Instituto do Milênio de Bioengenharia Tecidual-MCT, NIH (RO1 HL73732-01), CAPES/MEC, Ministerio da Saúde/Decit and CNPq. 


\section{References}

1. Volpe M, Tocci G. Integrated cardiovascular risk management for the future: lessons learned from the ASCOT trial. Aging Clin Exp Res 2005; 17: 46-53.

2. Anversa P, Li P, Zhang X, Olivetti G, Capasso JM. Ischaemic myocardial injury and ventricular remodelling. Cardiovasc Res 1993; 27: 145-157.

3. Sutton MG, Sharpe N. Left ventricular remodeling after myocardial infarction: pathophysiology and therapy. Circulation 2000; 101: 2981-2988.

4. Entman ML, Smith CW. Postreperfusion inflammation: a model for reaction to injury in cardiovascular disease. Cardiovasc Res 1994; 28: 1301-1311.

5. Frangogiannis NG, Youker KA, Rossen RD, Gwechenberger $\mathrm{M}$, Lindsey MH, Mendoza LH, et al. Cytokines and the microcirculation in ischemia and reperfusion. $\mathrm{J} \mathrm{Mol} \mathrm{Cell} \mathrm{Cardiol}$ 1998; 30: 2567-2576.

6. Mehta JL, Li DY. Inflammation in ischemic heart disease: response to tissue injury or a pathogenetic villain? Cardiovasc Res 1999; 43: 291-299.

7. Williams JG, Jurkovich GJ, Maier RV. Interferon-gamma: a key immunoregulatory lymphokine. J Surg Res 1993; 54: 79-93.

8. Cheng X, Liao YH, Ge H, Li B, Zhang J, Yuan J, et al. TH1/ $\mathrm{TH} 2$ functional imbalance after acute myocardial infarction: coronary arterial inflammation or myocardial inflammation. J Clin Immunol 2005; 25: 246-253.

9. Byrne CE, Fitzgerald A, Cannon CP, Fitzgerald DJ, Shields DC. Elevated white cell count in acute coronary syndromes: relationship to variants in inflammatory and thrombotic genes. BMC Med Genet 2004; 5: 13.

10. Torre-Amione G, Kapadia S, Benedict C, Oral H, Young JB, Mann DL. Proinflammatory cytokine levels in patients with depressed left ventricular ejection fraction: a report from the Studies of Left Ventricular Dysfunction (SOLVD). J Am Coll Cardiol 1996; 27: 1201-1206.

11. Frangogiannis NG, Entman ML. Chemokines in myocardial ischemia. Trends Cardiovasc Med 2005; 15: 163-169.

12. Frangogiannis NG, Smith CW, Entman ML. The inflammatory response in myocardial infarction. Cardiovasc Res 2002; 53: 31-47.

13. Mari D, Di Berardino F, Cugno M. Chronic heart failure and the immune system. Clin Rev Allergy Immunol 2002; 23: 325-340.

14. Jahns R, Boivin V, Krapf T, Wallukat G, Boege F, Lohse MJ. Modulation of beta1-adrenoceptor activity by domain-specific antibodies and heart failure-associated autoantibodies. $J$ Am Coll Cardiol 2000; 36: 1280-1287.

15. Gould KE, Taffet GE, Michael LH, Christie RM, Konkol DL, Pocius JS, et al. Heart failure and greater infarct expansion in middle-aged mice: a relevant model for postinfarction failure. Am J Physiol Heart Circ Physiol 2002; 282: H615-H621.

16. Gao XM, Dart AM, Dewar E, Jennings G, Du XJ. Serial echocardiographic assessment of left ventricular dimensions and function after myocardial infarction in mice. Cardiovasc Res 2000; 45: 330-338.

17. Eriksson S, Halenius H, Pulkki K, Hellman J, Pettersson K. Negative interference in cardiac troponin I immunoassays by circulating troponin autoantibodies. Clin Chem 2005; 51 : 839-847.

18. Nobrega A, Stransky B, Nicolas N, Coutinho A. Regeneration of natural antibody repertoire after massive ablation of lym- phoid system: robust selection mechanisms preserve antigen binding specificities. J Immunol 2002; 169: 2971-2978.

19. Szodoray P, Alex P, Brun JG, Centola M, Jonsson R. Circulating cytokines in primary Sjogren's syndrome determined by a multiplex cytokine array system. Scand J Immunol 2004; 59: 592-599.

20. lacobas DA, lacobas S, Urban-Maldonado M, Spray DC. Sensitivity of the brain transcriptome to connexin ablation. Biochim Biophys Acta 2005; 1711: 183-196.

21. lacobas DA, lacobas S, Li WE, Zoidl G, Dermietzel R, Spray DC. Genes controlling multiple functional pathways are transcriptionally regulated in connexin43 null mouse heart. Physiol Genomics 2005; 20: 211-223.

22. Dahlquist KD, Salomonis N, Vranizan K, Lawlor SC, Conklin BR. GenMAPP, a new tool for viewing and analyzing microarray data on biological pathways. Nat Genet 2002; 31: 19-20.

23. Doniger SW, Salomonis N, Dahlquist KD, Vranizan K, Lawlor SC, Conklin BR. MAPPFinder: using Gene Ontology and GenMAPP to create a global gene-expression profile from microarray data. Genome Biol 2003; 4: R7.

24. Lange LG, Schreiner GF. Immune mechanisms of cardiac disease. N Engl J Med 1994; 330: 1129-1135.

25. Smith SC, Allen PM. The role of T cells in myosin-induced autoimmune myocarditis. Clin Immunol Immunopathol 1993; 68: 100-106.

26. Varda-Bloom N, Leor J, Ohad DG, Hasin Y, Amar M, Fixler $\mathrm{R}$, et al. Cytotoxic $\mathrm{T}$ lymphocytes are activated following myocardial infarction and can recognize and kill healthy myocytes in vitro. J Mol Cell Cardiol 2000; 32: 2141-2149.

27. Matache C, Stefanescu M, Ivanov D, Szegli G, Popescu P, Filip Z. Presence and significance of some antibodies/ autoantibodies in patients with acute myocardial infarction and idiopathic dilated cardiomyopathy. Roum Arch Microbiol Immunol 1992; 51: 197-203.

29. Melguizo C, Prados J, Velez C, Aranega AE, Marchal JA, Aranega A. Clinical significance of antiheart antibodies after myocardial infarction. Jpn Heart J 1997; 38: 779-786.

29. Hosenpud JD, Campbell SM, Mendelson DJ. Interleukin-1induced myocardial depression in an isolated beating heart preparation. J Heart Transplant 1989; 8: 460-464.

30. Siwik DA, Chang DL, Colucci WS. Interleukin-1beta and tumor necrosis factor-alpha decrease collagen synthesis and increase matrix metalloproteinase activity in cardiac fibroblasts in vitro. Circ Res 2000; 86: 1259-1265.

31. Lyn D, Liu X, Bennett NA, Emmett NL. Gene expression profile in mouse myocardium after ischemia. Physiol Genomics 2000; 2: 93-100.

32. Nanni L, Romualdi C, Maseri A, Lanfranchi G. Differential gene expression profiling in genetic and multifactorial cardiovascular diseases. J Mol Cell Cardiol 2006; 41: 934-948.

33. Alvarez FL, Neu N, Rose NR, Craig SW, Beisel KW. Heartspecific autoantibodies induced by Coxsackievirus B3: identification of heart autoantigens. Clin Immunol Immunopathol 1987; 43: 129-139.

34. Matsui S, Fu ML, Katsuda S, Hayase M, Yamaguchi N, Teraoka K, et al. Peptides derived from cardiovascular G-protein-coupled receptors induce morphological cardiomyopathic changes in immunized rabbits. $\mathrm{J} \mathrm{Mol} \mathrm{Cell} \mathrm{Cardiol}$ 1997; 29: 641-655. 
35. Matsumori A, Kawai C. An experimental model for congestive heart failure after encephalomyocarditis virus myocarditis in mice. Circulation 1982; 65: 1230-1235.

36. Neu N, Rose NR, Beisel KW, Herskowitz A, Gurri-Glass G, Craig SW. Cardiac myosin induces myocarditis in genetically predisposed mice. J Immunol 1987; 139: 3630-3636.

37. Rupprecht HJ, Blankenberg S, Bickel C, Rippin G, Hafner G, Prellwitz W, et al. Impact of viral and bacterial infectious burden on long-term prognosis in patients with coronary artery disease. Circulation 2001; 104: 25-31.

Supplementary Table 1A. Genes involved in the inflammatory/immune defense response of mice whose absolute difference exceeds 1.5-fold but with $\mathrm{P}>0.05$.

\begin{tabular}{|c|c|c|c|}
\hline Name & Symbol & $x$ & $P$ \\
\hline CD276 antigen (Cd276) & Cd276 & 1.58 & 0.053 \\
\hline Chemokine (C-C motif) ligand 17 & Ccl17 & 1.67 & 0.061 \\
\hline Chemokine (C-C motif) ligand 5 & Ccl5 & 1.63 & 0.172 \\
\hline Chemokine (C-C motif) ligand 6 & Ccl6 & 3.29 & 0.085 \\
\hline Chemokine (C-C motif) receptor 2 & Ccr2 & 1.81 & 0.100 \\
\hline Chemokine (C-C motif) receptor-like 1 & Ccrl1 & 2.28 & 0.134 \\
\hline Chemokine (C-X3-C motif) ligand 1 & $\mathrm{Cx} 3 \mathrm{cl} 1$ & 1.67 & 0.133 \\
\hline Chemokine (C-X-C motif) ligand 12, transcript variant 1 & Cxcl12 & -1.93 & 0.196 \\
\hline Chemokine (C-X-C motif) ligand 16 & Cxcl16 & 1.69 & 0.139 \\
\hline Chemokine (C-X-C motif) ligand 7 & $\mathrm{Cxcl} 7$ & 3.31 & 0.144 \\
\hline Chemokine-like factor superfamily $2 \mathrm{~A}$ & Cklfsf2a & -1.72 & 0.238 \\
\hline Cytokine receptor-like factor 1 & Crlf1 & 1.77 & 0.135 \\
\hline Duffy blood group & Dfy & 2.16 & 0.062 \\
\hline Fas (TNF receptor superfamily member) & Fas & 2.13 & 0.056 \\
\hline Interferon gamma inducible protein 47 & Ifi47 & 1.53 & 0.179 \\
\hline Interferon induced 203 protein & Ifi203 & 1.92 & 0.096 \\
\hline Interferon induced transmembrane protein 1 & Ifitm1 & 1.77 & 0.146 \\
\hline Interferon regulatory factor 1 & Irf1 & 1.54 & 0.128 \\
\hline Interferon-related developmental regulator 1 & Ifrd1 & 1.83 & 0.106 \\
\hline Interleukin 1 beta & $\| 1 \mathrm{~b}$ & 2.07 & 0.127 \\
\hline Interleukin 1 receptor accessory protein, transcript variant 1 & ॥1rap & 1.97 & 0.067 \\
\hline Interleukin 10 receptor, alpha & II10ra & 1.64 & 0.083 \\
\hline Interleukin 15 receptor, alpha chain, transcript variant 1 & II15ra & 1.73 & 0.102 \\
\hline Interleukin 17 receptor & $\| 17 r$ & 1.99 & 0.059 \\
\hline Interleukin 17 receptor B & Il17rb & 2.01 & 0.064 \\
\hline Interleukin 17 receptor $\mathrm{E}$ & II17re & 3.53 & 0.224 \\
\hline Interleukin 17E & $\| 17 \mathrm{e}$ & -1.85 & 0.354 \\
\hline Interleukin 17F & $\| 17 f$ & -1.50 & 0.428 \\
\hline Interleukin 18 receptor 1 & II18r1 & 2.31 & 0.097 \\
\hline Interleukin 2 receptor, alpha chain & II2ra & 1.82 & 0.134 \\
\hline Interleukin 31 & $\| 31$ & 1.58 & 0.179 \\
\hline Interleukin 4 receptor, alpha, transcript variant 2 & $\| 4 \mathrm{ra}$ & 2.15 & 0.066 \\
\hline Lymphocyte antigen 86 & Ly86 & 1.56 & 0.092 \\
\hline Peroxisome proliferator activated receptor gamma & Pparg & 2.06 & 0.143 \\
\hline Replication initiator 1 & Repin1 & 1.72 & 0.095 \\
\hline Toll-like receptor 3 & TIr3 & 1.79 & 0.052 \\
\hline Tumor necrosis factor (ligand) superfamily, member 13 & Tnfsf13 & 1.94 & 0.074 \\
\hline Tumor necrosis factor (ligand) superfamily, member 15 & Tnfsf15 & -1.56 & 0.348 \\
\hline Tumor necrosis factor receptor superfamily, member 23 & Tnfrsf23 & 1.57 & 0.137 \\
\hline Tumor necrosis factor, alpha-induced protein 2 & Tnfaip2 & 1.60 & 0.052 \\
\hline Tumor necrosis factor, alpha-induced protein 8-like 2 & Tnfaip8I2 & 1.86 & 0.140 \\
\hline Uveal autoantigen with coiled-coil domains and ankyrin repeats & Uaca & 1.58 & 0.074 \\
\hline
\end{tabular}

$X=$ fold difference (negative values indicate down-regulation of the transcript). The Student heteroscedastic $t$-test was used for the comparison of myocardial infarction with control. 
Supplementary Table 1B. Non-regulated genes involved in the inflammatory/immune defense response of mice.

\begin{tabular}{|c|c|c|c|c|c|c|c|}
\hline Name & Symbol & $\mathrm{x}$ & $P$ & Name & Symbol & $x$ & $\mathrm{P}$ \\
\hline Allograft inflammatory factor 1 & Aif1 & 1.36 & 0.152 & Interferon, alpha-inducible protein & G1p2 & -1.17 & 0.518 \\
\hline Arachidonate 5-lipoxygenase & Alox5 & 1.28 & 0.494 & Interferon, alpha-inducible protein 27 & Ifi27 & -1.07 & 0.750 \\
\hline Attractin & Atrn & -1.11 & 0.475 & Interferon-activatable protein 203 & N/A & 1.08 & 0.715 \\
\hline CD180antigen & Cd180 & 1.18 & 0.252 & Interferon-induced protein 44 & Ifi44 & -1.21 & 0.431 \\
\hline Chemokine ligand 12 & Ccl12 & -1.07 & 0.803 & Interferon-induced protein with tetratricopeptide repeats 1 & Ifit1 & 1.04 & 0.868 \\
\hline Chemokine ligand 2 & $\mathrm{Ccl} 2$ & 1.03 & 0.882 & Interferon-induced protein with tetratricopeptide repeats 2 & Ifit2 & 1.28 & 0.332 \\
\hline Chemokine ligand 22 & $\mathrm{Ccl} 22$ & -1.13 & 0.715 & Interferon-induced protein with tetratricopeptide repeats 3 & Ifit3 & -1.02 & 0.862 \\
\hline Chemokine ligand 24 & $\mathrm{Ccl} 24$ & 1.09 & 0.678 & Interferon-lambda2 & Ifnl2 & -1.46 & 0.047 \\
\hline Chemokine ligand 25 & $\mathrm{Ccl} 25$ & 1.25 & 0.126 & Interferon-related developmental regulator 2 & Ifrd2 & 1.21 & 0.312 \\
\hline Chemokine ligand 3 & $\mathrm{Ccl} 3$ & 1.03 & 0.959 & Interleukin 1 receptor-like 1 , transcript variant 1 & $\| 1 \mathrm{rl} 1$ & 1.30 & 0.329 \\
\hline Chemokine receptor 5 & Ccr5 & 1.31 & 0.163 & Interleukin 10 & $\| 10$ & 1.18 & 0.720 \\
\hline Chemokine receptor-like 2 & Ccrl2 & 1.10 & 0.639 & Interleukin 10 receptor, beta & ॥l10rb & 1.34 & 0.211 \\
\hline Chemokine ligand 1 & Cxcl1 & 1.42 & 0.282 & Interleukin $12 b$ & $\| 12 b$ & 1.24 & 0.507 \\
\hline Chemokine ligand 4 & $\mathrm{Cxcl} 4$ & 1.30 & 0.252 & Interleukin 15 & ॥15 & 1.23 & 0.239 \\
\hline Chemokine ligand 9 & Cxcl9 & 1.00 & 0.990 & Interleukin 16 & $\| 16$ & 1.49 & 0.048 \\
\hline Chemokine receptor 4 & Cxcr4 & 1.49 & 0.079 & Interleukin 17 & $\| 17$ & 1.14 & 0.720 \\
\hline Chemokine receptor 6 & Cxcr6 & -1.42 & 0.407 & Interleukin 17 receptor $\mathrm{c}$ & $\| 17 \mathrm{rc}$ & 1.50 & 0.015 \\
\hline Chemokine binding protein 2 & Ccbp2 & 1.29 & 0.272 & Interleukin 17 receptor $\mathrm{d}$ & Il17rd & 1.13 & 0.704 \\
\hline Chemokine-like factor 5 , complete cds & CKLF5 & 1.02 & 0.915 & Interleukin $17 \mathrm{~d}$ & $\| 17 d$ & 1.02 & 0.851 \\
\hline Chemokine-like factor superfamily $2 \mathrm{~B}$ & Cklfsf2b & 1.31 & 0.170 & Interleukin 18 & ॥18 & 1.46 & 0.124 \\
\hline Chemokine-like factor superfamily 3 & Cklfsf3 & 1.31 & 0.066 & Interleukin 18 binding protein & $\| 18 b p$ & 1.36 & 0.171 \\
\hline Chemokine-like factor superfamily 4 & Cklfsf4 & 1.22 & 0.292 & Interleukin 21 & $N / A$ & 1.28 & 0.391 \\
\hline Chemokine-like factor superfamily 5 & Cklfsf5 & -1.28 & 0.577 & Interleukin 21 receptor & $\| 21 \mathrm{r}$ & 1.20 & 0.549 \\
\hline Chemokine-like factor superfamily 6 & Cklfsf6 & 1.49 & 0.072 & Interleukin 4 induced 1 & $\| 4 \mathrm{i} 1$ & -1.45 & 0.217 \\
\hline Chemokine-like factor superfamily 7 & Cklfsf7 & 1.19 & 0.018 & Interleukin 6 receptor, alpha & $\Perp 6 r a$ & 1.46 & 0.220 \\
\hline Chemokine-like factor superfamily 8 & Cklfsf8 & -1.01 & 0.924 & Interleukin 7 & 117 & 1.29 & 0.174 \\
\hline Chemokine-like factor, transcript variant 1 & Cklf & 1.22 & 0.305 & Interleukin 7 receptor & $\| 17 r$ & -1.50 & 0.724 \\
\hline Chitinase 3-like 4 & Chi314 & 1.06 & 0.808 & Interleukin enhancer binding factor 3 & IIf3 & 1.36 & 0.134 \\
\hline Cytokine induced apoptosis inhibitor 1 & Ciapin1 & 1.25 & 0.231 & Interleukin-1 receptor associated kinase 1 splice form 1 & Irak1 & 1.37 & 0.055 \\
\hline Cytokine inducible SH2-containing protein & Cish & -1.02 & 0.921 & Interleukin-1 receptor-associated kinase 1 binding protein 1 & Iraklbp1 & 1.06 & 0.830 \\
\hline Cytokine-like 1 & Cyt1 & 1.37 & 0.039 & Myeloid differentiation primary response gene 88 & Myd88 & -1.01 & 0.916 \\
\hline Cytokine receptor-like factor 3 & Crlf3 & 1.21 & 0.521 & Pyd and card domain containing & Pycard & -1.04 & 0.806 \\
\hline $\begin{array}{l}\text { Endothelial differentiation, sphingolipid G-protein- } \\
\text { coupled receptor, } 3\end{array}$ & Edg3 & 1.49 & 0.175 & Regenerating islet-derived 3 gamma & Reg3g & 1.33 & 0.299 \\
\hline Hemolytic complement & $\mathrm{Hc}$ & 1.14 & 0.558 & Signal transducer and activator of transcription $5 b$ & Stat5b & 1.21 & 0.385 \\
\hline Interferon receptor 2 & Ifnar2 & 1.20 & 0.347 & Tachykinin 1 & Tac1 & 1.08 & 0.839 \\
\hline Interferon-activated gene 203 & Ifi203 & 1.17 & 0.195 & Toll-like receptor 1 & TIr1 & -1.31 & 0.316 \\
\hline Interferon alpha responsive gene & Ifrg15 & 1.25 & 0.487 & Toll-like receptor 9 & TIr9 & 1.32 & 0.096 \\
\hline $\begin{array}{l}\text { Interferon-dependent positive acting transcription } \\
\text { factor } 3 \text { gamma }\end{array}$ & Isgf3g & -1.22 & 0.821 & Transforming growth factor, beta 1 & Tgfb1 & 1.35 & 0.062 \\
\hline Interferon gamma-induced gtpase & Igtp & 1.20 & 0.292 & Tumor necrosis factor superfamily, member 12 & Tnfsf12 & 1.43 & 0.099 \\
\hline Interferon gamma-inducible protein 30 & Ifi30 & 1.18 & 0.517 & Tumor necrosis factor superfamily, member $13 b$ & Tnfsf13b & 1.32 & 0.385 \\
\hline Interferon-induced transmembrane protein 2 & Ifitm2 & 1.29 & 0.051 & Tumor necrosis factor superfamily, member 9 & Tnfsf9 & 1.38 & 0.353 \\
\hline Interferon-induced transmembrane protein 3 & Ifitm3 & -1.12 & 0.301 & Tumor necrosis factor receptor superfamily, member 19 & Tnfrsf19 & 1.24 & 0.191 \\
\hline Interferon-inducible gtpase 2 & ligp2 & 1.32 & 0.123 & Tumor necrosis factor receptor superfamily, member 21 & Tnfrsf21 & 1.29 & 0.392 \\
\hline Interferon-inducible gtpase family member 5 & ligp5 & -1.02 & 0.936 & Tumor necrosis factor receptor superfamily, member 4 & Tnfrsf4 & 1.02 & 0.914 \\
\hline Interferon regulatory factor 2 & Irf2 & 1.31 & 0.219 & Tumor necrosis factor receptor superfamily, member 5 & Tnfrsf5 & 1.28 & 0.035 \\
\hline Interferon regulatory factor 2 binding protein 1 & Irf2bp1 & 1.01 & 0.956 & Tumor necrosis factor receptor superfamily, member 9 & Tnfrsf9 & -1.11 & 0.724 \\
\hline Interferon regulatory factor 2 binding protein 2 & Irf2bp2 & 1.12 & 0.682 & Tumor necrosis factor superfamily, member 5 -induced protein 1 & Tnfsf5ip1 & 1.26 & 0.155 \\
\hline Interferon regulatory factor 5 & Irf5 & 1.35 & 0.194 & Tumor necrosis factor, alpha-induced protein 1 & Tnfaip1 & 1.31 & 0.037 \\
\hline Interferon regulatory factor 6 , transcript variant 1 & Irf6 & -1.14 & 0.732 & Tumor necrosis factor, alpha-induced protein 3 & Tnfaip3 & 1.43 & 0.152 \\
\hline Interferon regulatory factor 7 & Irf7 & -1.03 & 0.875 & Tumor necrosis factor, alpha-induced protein 8 & Tnfaip8 & 1.19 & 0.197 \\
\hline Interferon stimulated exonuclease gene 20-like 1 & Isg20|1 & 1.22 & 0.414 & Tumor necrosis factor, alpha-induced protein 8-like 1 & Tnfaip8l1 & 1.19 & 0.409 \\
\hline
\end{tabular}

$X=$ fold difference (negative values indicate down-regulation of the transcript). The Student heteroscedastic $t$-test was used for the comparison of heart failure with control. 